\title{
A case of traumatic intracranial vertebral artery injury presenting with life-threatening symptoms
}

This article was published in the following Dove Press journal:

International Medical Case Reports Journal

21 April 2012

Number of times this article has been viewed

\author{
Seiji Kishi' \\ Kenji Kanaji² \\ Toshio Doi' \\ Tadashi Matsumura ${ }^{2}$ \\ 'Department of Nephrology, \\ Tokushima University Hospital, \\ Kuramoto-cho Tokushima, \\ ${ }^{2}$ Department of General Internal \\ Medicine, Rakuwakai Otowa Hospital, \\ Otowachinji-cho Yamashina-ku Kyoto, \\ Japan
}

Correspondence: Seiji Kishi Department of Nephrology, Tokushima University Hospital, 2-50-I Kuramoto-cho Tokushima 770-8503, Japan

Tel +8I $886337 \mid 84$

Fax +8I 886339245

Email s_kishi@clin.med.tokushima-u.ac.jp
Abstract: Traumatic intracranial vertebral artery injury is a relatively rare but potentially fatal disease. We present a case of a 63 -year-old man who presented with sudden onset of loss of consciousness after hitting his head. After immediate resuscitation, he showed quadriplegia and absence of spontaneous breathing. Brain and cervical spine magnetic resonance imaging revealed an atlantoaxial subluxation, fractured $\mathrm{C} 2$ odontoid process, left vertebral artery occlusion, and bilateral extensive ischemia in the medulla oblongata and high cervical spinal cord. Digital subtraction angiography demonstrated left vertebral artery dissection just below the level of vertebral body $\mathrm{C} 2$.

Keywords: vertebral artery dissection, brainstem infarction, bilateral spinal cord infarction, neck trauma

\section{Introduction}

Vertebral artery dissection is a common cause of ischemic stroke in young adults and is categorized as either spontaneous or traumatic. ${ }^{1}$ Traumatic vertebral artery dissection may be caused by major penetrating or blunt neck trauma. The incidence of vertebral artery injury among patients with blunt neck trauma is estimated at $0.20 \%-0.77 \% .^{2}$ Major mechanisms of injury are distraction/extension, distraction/flexion, and lateral flexion. The vertebral artery is easily injured by traction. ${ }^{3}$ However, only about $12 \%-24 \%$ of unilateral vertebral artery injuries present with signs and symptoms of vertebrobasilar ischemia. Patients with suspected cervical trauma should be examined thoroughly. Definitive diagnosis is made with imaging methods like magnetic resonance imaging, magnetic resonance angiography, and digital subtraction angiography. We present a case of traumatic vertebral artery dissection presenting with life-threatening symptoms.

\section{Case presentation}

A 63-year-old man, while under the influence of alcohol, fell on an icy sidewalk and hit his head. He suffered sudden onset of loss of consciousness and was transported to the hospital. He had a past medical history of an unspecified neck surgery. There was no previous use of medications or previous infectious symptoms. He was a nonsmoker, did not have diabetes, and was normotensive. There was no family history of thrombophilia or venous thromboembolism.

At the emergency room he was in respiratory arrest with severe hypotension and bradycardia. His body temperature was low $\left(33.8^{\circ} \mathrm{C}\right)$. His pupils were dilated and 
his Glasgow Coma Scale score was 3 (E1, V1, M1). After immediate respiratory and circulatory management, he was admitted. He needed mechanical ventilation and intravenous pressors because of sustained hypotension. There was no evidence of hemorrhagic shock. Head computed tomography scans, chest and cervical portable radiography, electrocardiography, and echocardiography were unremarkable. Laboratory data were unremarkable except for hyperglycemia $(240 \mathrm{mg} / \mathrm{dL})$ and elevated creatine phosphokinase (352 IU/L). A lumbar puncture showed cerebrospinal fluid protein of $86 \mathrm{mg} / \mathrm{dL}$ and glucose of $124 \mathrm{mg} / \mathrm{dL}$ (blood glucose $204 \mathrm{mg} / \mathrm{dL}$ ). There were five white cells and no xanthochromia in $10 \mathrm{~mL}$ of cerebrospinal fluid. Seven hours later, a subarachnoid hemorrhage was detected following computed tomography scans (Figure 1), and repeat lumbar puncture showed xanthochromia. A cervical spine computed tomography scan showed a fractured $\mathrm{C} 2$ odontoid process. We treated him as a high spinal cord injury but failed to detect any reason for the patient's unconsciousness.

By the third hospital day, the patient showed some improvement, with a Glasgow Coma Scale score of 6 (E4, V1, M1) without spontaneous breathing. The pupils were equal with normal light reflexes. Horizontal saccadic and smooth pursuit were disturbed bilaterally. Caloric nystagmus was provoked normally, and Bell's phenomenon was preserved. Facial sensation and movement showed no asymmetry.

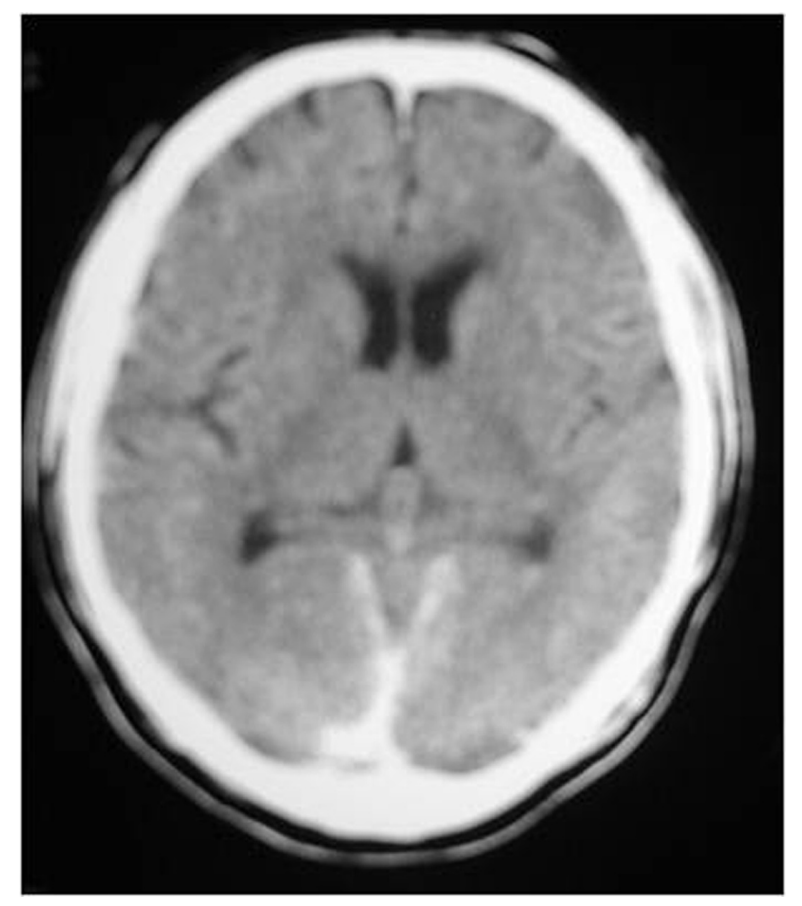

Figure I Axial noncontrast head CT demonstrated hyperdense material within superior sagittal sinus.

Abbreviation: CT, computed tomography.
He was quadriplegic and there was no sensation below the neck. We performed brain and cervical spine magnetic resonance imaging to evaluate central nervous system damage further. T2-short tau inversion recovery images showed disappearance of flow in the left vertebral artery and a hyperintense lesion in the spinal cord (Figure 2A). Axial T2 imaging revealed the hyperintense lesion involving the medial medulla bilaterally, and sagittal T2-weighted images revealed atlantoaxial subluxation, a fractured $\mathrm{C} 2$ odontoid process, and a hyperintense lesion extending from the medulla to $\mathrm{C} 5$ (Figure 2B and C). Digital subtraction angiography showed that the left vertebral artery terminated just below the level of vertebral body C2 (Figure 3). A diagnosis of medial medullary and upper spinal cord infarction due to traumatic left vertebral artery dissection was made, but no endovascular therapy was attempted.

After diagnosis he underwent a tracheotomy for respiratory management and nasogastric feeding was started. Antiplatelet therapy was not given because he developed a subarachnoid hemorrhage during the clinical course. His general condition and neurological functions did not improve. Three months after diagnosis, he died because of uncontrollable bleeding from a gastric ulcer.

\section{Discussion}

Our patient demonstrates a rare and severe case of vertebral artery dissection-associated medulla oblongata and bilateral spinal cord infarction with sudden onset of respiratory arrest and quadriplegia associated with upper cervical spine trauma. Vertebral artery dissection usually leads to symptoms caused by vertebrobasilar ischemia affecting the posterior circulation, but few cases of vertebrobasilar ischemia in patients with cervical spine trauma have been reported previously. ${ }^{9-17}$ There are even fewer reported cases of intracranial vertebral artery dissection compared with extracranial dissection. ${ }^{4-8}$

On the other hand, clinical features seen in patients with bilateral medial medullary infarction include quadriplegia or hemiplegic distribution of weakness, unilateral or bilateral lingual paresis, facial palsy, hypoesthesia, respiratory paralysis, oculomotor disturbances, sensory ataxia, vestibular features, dysarthria, and dysphagia. The combination of medullary and cervical spinal cord ischemia due to vertebral artery dissection is uncommon. ${ }^{18,19}$ Vertebral artery dissection or vertebral artery occlusion is rarely symptomatic because of sufficient collateral blood supply through the contralateral vertebral artery, as in this case. However, if embolic strokes occur, severe neurological symptoms, including the so-called "top of the basilar syndrome", are possible with vertebral 

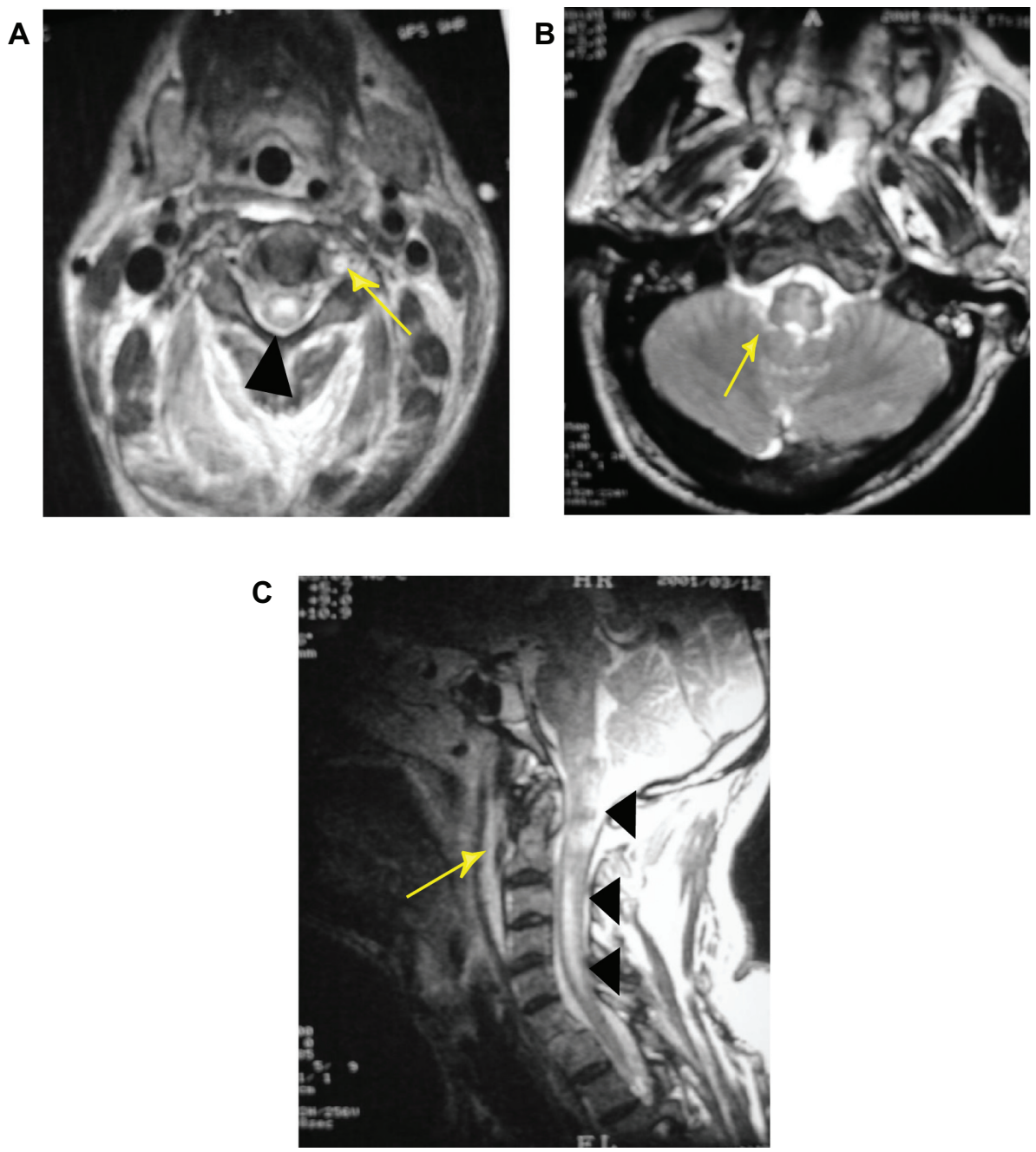

Figure 2 (A) T2-STIR image demonstrates hyperintensity in left vertebral artery consistent with slowly flowing blood or occlusion (arrow) and hyperintense lesion in spinal cord (arrow head). (B) Axial T2 image showing hyperintense lesion involving bilateral medial medulla (arrow). (C) Sagittal T2-weighted image showing atlantoaxial subluxation, fractured $\mathrm{C} 2$ odontoid process (arrow) and hyperintense lesion extending from medulla to $\mathrm{C} 5$ (arrowheads).
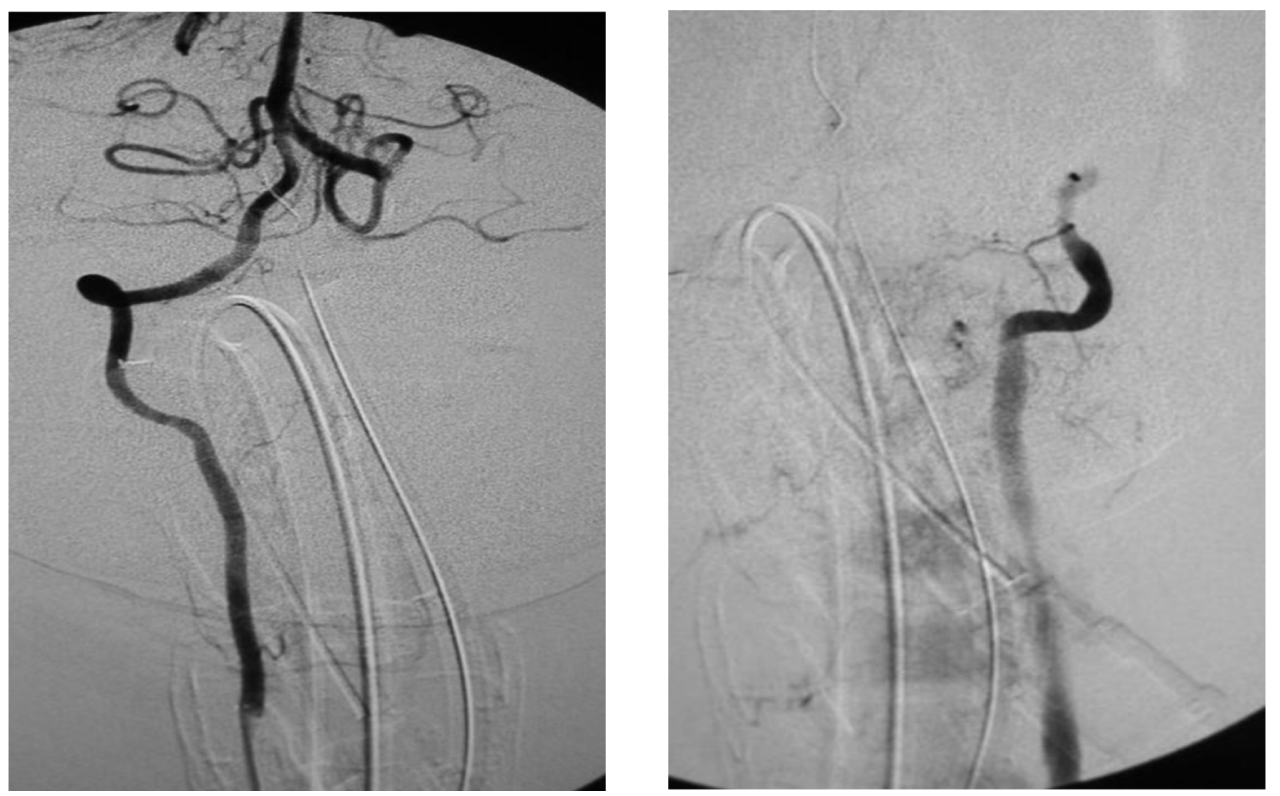

Figure 3 Anteroposterior vertebral arteriograms showing the left vertebral artery occludes and contrast flowstops within the cervical vertebral artery. 
artery dissection. The thrombi at the injured arterial site may break free and shower emboli throughout the posterior circulation. Therefore, if we had performed digital subtraction angiography at the onset, we could have detected an embolic occlusion at the top of the basilar artery as a result of thrombi from the injured arterial site. Another consideration should be the role of direct impact to the spinal cord causing a central cord type lesion, thus possibly explaining the part of his lesion which could not be accounted for by problems with the blood supply. Furthermore, medial medullary infarction is rare and occurs in fewer than $1 \%$ of all vertebral artery strokes. ${ }^{20}$ Bilateral medial medullary infarcts are even rarer, and have a dismal prognosis..$^{21,22}$

The diagnosis of traumatic vertebral artery dissection is reserved for those patients with a history of significant trauma, including motor vehicle accidents, falls, or penetrating injuries. Despite the severity of the injury mechanism, dissections of the vertebral artery are exceedingly rare. The two vertebral arteries, together with the basilar artery, are the main blood supply to the posterior circulation of the brain. The vertebral arteries are divided into four segments anatomically. Segment I runs from its takeoff at the first branch of the subclavian artery to the transverse foramina of cervical vertebra C5 or C6. Segment II runs entirely within the transverse foramina of C5/C6 to C2. Segment III begins at the transverse foramen of $\mathrm{C} 2$, runs posterolaterally to loop around the posterior arch of $\mathrm{C} 1$, and passes subsequently between the atlas and the occiput. Segment IV is the intracranial segment. According to previous studies, most of the traumatic dissections involve Segment III. ${ }^{23}$ Our case also involved Segment III. The proximity of the vertebral artery to the lateral mass of the $\mathrm{C} 2$ vertebral body and the ring of the $\mathrm{C} 1$ vertebral body is thought to be an important factor in the pathogenesis of vertebral artery dissections related to neck motion. ${ }^{24}$ This segment is encased in muscles and nerves. The atlanto-occipital membrane represents the segment of interest in our series. This may be secondary to the relative anchoring of the vessel at the $\mathrm{C} 2$ foramen transversarium and the dura. Although the true incidence of the condition and its significance remains unclear, blunt vertebral artery injury is associated with complex cervical spine fractures involving subluxation, extension into the foramen transversarium, or upper C1 to $\mathrm{C} 3$ fractures. ${ }^{25}$

Dissection of a cervicocephalic artery is caused by a rupture within the arterial wall leading to an intramural hematoma. The pathogenesis of vertebral artery dissection in these cases is not fully understood and there is no universal agreement as to which wall is the primary site of dissection. Vertebral artery dissection are often preceded by some form of trauma to the neck. However, the severity of trauma can range from a trivial injury to severe roadside accidents involving direct injury to the neck arteries.

The best therapeutic strategy for intracranial vertebral artery dissection remains unclear and there is currently no consensus on the proper management strategy. In recent years, advances in screening and treatment with anticoagulation and antiplatelet therapy before the onset of neurologic symptoms have improved outcomes for these patients except when arterial transections of the vertebral arteries or absolute contraindications to systemic anticoagulation, such as significant brain injury with intracranial hemorrhage, are present. ${ }^{26-28}$ These observations suggest that treatment in the acute phase should be focused more on preventing progression or recurrence of ischemic stroke than on preventing subarachnoid hemorrhage, especially in patients with ischemic presentations. The existence of ischemic presentation is related to unfavorable clinical outcomes. ${ }^{28}$ Currently recommended treatments for vertebral artery dissection include anticoagulation, antiplatelet treatment, and thrombolysis. ${ }^{4,29}$ A meta-analysis of 24 studies showed nonsignificant difference in case fatality and survival rates between anticoagulation and antiplatelet treatment. ${ }^{30}$ Thrombolysis is an optional regimen for acute vascular occlusion. Endovascular stenting, coiling, and embolization, although unproven, offer a potential new approach for these complex injuries. ${ }^{31,32}$ When the patients received endovascular treatment, deconstructive or reconstructive treatment was given. Deconstructive treatments sacrifice the parent artery, and include proximal occlusion or internal coil trapping of the parent artery. Reconstructive treatments preserve the parent artery patency using stents, with or without coiling. The treatment type was determined on a case-by-case basis at each interventional neuroradiologist's discretion according to the presenting symptoms, hemodynamic status, lesion type, and anatomic factors of the vertebrobasilar artery. Although there are limited data, endovascular management of extracranial arterial dissection should also be considered in patients with contraindications to antithrombotic agents of any kind or who fail medical therapy. ${ }^{33}$ Thus, the improvement of endovascular management technology is evident, and we should also discuss the indications for endovascular treatment when we see patients with intracranial vertebral artery dissection. The use of surgical methods in the form of thrombectomy, bypass, or ligation procedures, has been reported, but overall the role of surgery seems to be small and shrinking. ${ }^{34}$

Although our patient was immediately paralyzed and ventilated, with unstable vital signs, earlier pursuit of an 
active diagnosis by magnetic resonance imaging or digital subtraction angiography might have been useful for developing a treatment plan to improve his outcome by using endovascular or surgical treatment. Unfortunately, we could not perform anticoagulation or antiplatelet therapy due to a subarachnoid hemorrhage, but endovascular treatment, as other choices, could have led to improvement of the neurological and overall prognosis in this case.

In conclusion, early recognition of vertebral artery injury is important to prevent permanent neurologic damage, with early institution of therapy, such as anticoagulation, antiplatelet, or surgical therapy, including endovascular treatment. Even if the patient is severely ill, the physician should consider diagnostic modalities which might lead to an accurate diagnosis, and the selection of treatment regimens should depend on the clinical manifestations and imaging findings.

\section{Acknowledgment}

We thank George W Meyer for critical reading of the manuscript and Takashi Kawanaka, Department of Radiology, University of Tokushima, for interpretation of magnetic resonance imaging.

\section{Disclosure}

The authors state that they have no conflicts of interest in this work.

\section{References}

1. Savitz SI, Caplan LR. Vertebrobasilar disease. $N$ Engl J Med. 2005;352(25):2618-2626.

2. Inamasu J, Guiot BH. Vertebral artery injury after blunt cervical trauma: an update. Surg Neurol. 2006;65(3):238-245.

3. Khurana DS, Bonnemann CG, Dooling EC, Ouellette EM, Buonanno F. Vertebral artery dissection: issues in diagnosis and management. Pediatr Neurol. 1996;14(3):255-258.

4. Vaccaro AR, Klein GR, Flanders AE, Albert TJ, Balderston RA, Cotler JM. Long-term evaluation of vertebral artery injuries following cervical spine trauma using magnetic resonance angiography. Spine. 1998;23(7):789-794.

5. Willis BK, Greiner F, Orrison WW, Benzel EC. The incidence of vertebral artery injury after midcervical spine fracture or subluxation. Neurosurgery. 1994;34(3):435-442.

6. Friedman D, Flanders A, Thomas C, Millar W. Vertebral artery injury after acute cervical spine trauma: Rate of occurrence as detected by MR angiography and assessment of clinical consequences. AJR Am J Roentgenol. 1995;164(2):443-447.

7. Giacobetti FB, Vaccaro AR, Bos-Giacobetti MA, et al. Vertebral artery occlusion associated with cervical spine trauma. A prospective analysis. Spine. 1997;22(2):188-192.

8. Veras LM, Pedraza-Gutierrez S, Castellanos J, Capellades J, Casamitjana J, Rovira-Cañellas A. Vertebral artery occlusion after acute cervical spine trauma. Spine. 2000;25(9):1171-1177.

9. Parbhoo AH, Govender S, Corr P. Vertebral artery injury in cervical spine trauma. Injury. 2001;32(7):565-568.
10. Weller SJ, Rossitch E, Malek AM. Detection of vertebral artery injury after cervical spine trauma using magnetic resonance angiography. J Trauma. 1999;46(4):660-666.

11. Louw JA, Mafoyane NA, Small B, Neser CP. Occlusion of the vertebral artery in cervical spine dislocation. J Bone Joint Surg. 1990;72(4):679-681.

12. Rodriguez M, Tyberghien A, Matgé G. Asymptomatic vertebral artery injury after acute cervical spine trauma. Acta Neurochir (Wien). 2001;143(9):939-945.

13. Schievink WI. Spontaneous dissection of the carotid and vertebral arteries. N Engl J Med. 2001;344(12):898-906.

14. de Bray JM, Pnisson-Besnier I, Dubas F, Emile J. Extracranial and intracranial vertebrobasilar dissections: diagnosis and prognosis. J Neurol Neurosurg Psychiatry. 1997;63(1):46-51.

15. Caplan LR, Baquis GD, Pessin MS, et al. Dissection of the intracranial vertebral artery. Neurology. 1988;38(6):868-877.

16. Pelkonen O, Tikkakoski T, Leinonen S, Pyhtinen J, Sotaniemi K. Intracranial arterial dissection. Neuroradiology. 1998;40(7):442-447.

17. Hosoya T, Adachi M, Yamaguchi K, Haku T, Kayama T, Kato T. Clinical and neuroradiological features of intracranial vertebrobasilar artery dissection. Stroke. 1999;30(5):1083-1090.

18. Crum B, Mokri B, Fulgham J. Spinal manifestations of vertebral artery dissection. Neurology. 2000;55(2):304-306.

19. de la Sayette V, Leproux F, Letellier P. Cervical cord and dorsal medullary infarction presenting with retro-orbital pain. Neurology. 1999;53(3):632-634.

20. Kumral E, Afsar N, Kirbas D, Balkir K, Ozdemirkiran T. Spectrum of medial medullary infarction: clinical and magnetic resonance imaging findings. J Neurol. 2002;249(1):85-93.

21. Jagiella WM, Sung JH. Bilateral infarction of the medullary pyramids in humans. Neurology. 1989;39(1):21-24.

22. Kleinert G, Fazekas F, Kleinert R, et al. Bilateral medial medullary infarction: magnetic resonance imaging and correlative histopathologic findings. Eur Neurol. 1993;33(1):74-76.

23. Mokri B, Houser OW, Sandok BA, Piepgras DG. Spontaneous dissections of the vertebral arteries. Neurology. 1988;38(6):880-885.

24. Provenzale JM, Morgenlander JC, Gress D. Spontaneous vertebral dissection: clinical, conventional angiographic, CT, and MR findings. J Comput Assist Tomogr. 1996;20(2):185-193.

25. Ramgren B, Cronqvist M, Romner B, Brandt L, Holtas S, Larsson EM Vertebrobasilar dissection with subarachnoid hemorrhage: a retrospective study of 29 patients. Neuroradiology. 2005;47(2):97-104.

26. Biffl WL, Moore EE, Elliott JP, et al. The devastating potential of blunt vertebral arterial injuries. Ann Surg. 2000;231(5):672-681.

27. Biffl WL, Ray CE Jr, Moore EE, et al. Treatment-related outcomes from blunt cerebrovascular injuries: importance of routine follow-up arteriography. Ann Surg. 2002;235(5):699-706.

28. Kim BM, Kim SH, Kim DI, et al. Outcomes and prognostic factors of intracranial unruptured vertebrobasilar artery dissection. Neurology. 2011;76(20):1735-1741.

29. Dziewas R, Konrad C, Dräger B, et al. Cervical artery dissection clinical features, risk factors, therapy and outcome in 126 patients. J Neurol. 2003;250(10):1179-1184.

30. Lyrer P, Engelter S. Antithrombotic drugs for carotid artery dissection. Stroke. 2004;35(2):613-614.

31. Keilani ZM, Berne JD, Agko M. Bilateral internal carotid and vertebral artery dissection after a horse-riding injury. J Vasc Surg. 2010;52(4):1052-1057.

32. Sadato A, Maeda S, Hayakawa M, et al. Endovascular treatment of vertebral artery dissection using stents and coils: its pitfall and technical considerations. Minim Invasive Neurosurg. 2010;53(5-6):243-249.

33. Pham MH, Rahme RJ, Arnaout O, et al. Endovascular stenting of extra cranial carotid and vertebral artery dissections: a systematic review of the literature. Neurosurgery. 2011;68(4):856-866.

34. Cogbill TH, Moore EE, Meissner M, et al. The spectrum of blunt injury to the carotid artery: a multicenter perspective. $J$ Trauma. 1994;37(3):473-479. 


\section{Publish your work in this journal}

The International Medical Case Reports Journal is an international, peer-reviewed open-access journal publishing original case reports from all medical specialties. Previously unpublished medical posters are also accepted relating to any area of clinical or preclinical science. Submissions should not normally exceed 2,000 words or

4 published pages including figures, diagrams and references. The manuscript management system is completely online and includes a very quick and fair peer-review system, which is all easy to use. Visit http://www.dovepress.com/testimonials.php to read real quotes from published authors.

Submit your manuscript here: http://www.dovepress.com/international-medical-case-reports-journal-journal 